\title{
From the Sea to the Field: The Case Study of the Mycobiota Associated to the Marine Sponge Haliclona fulva and Its Interest as Biocontrol Agent Source for Agriculture ${ }^{\dagger}$
}

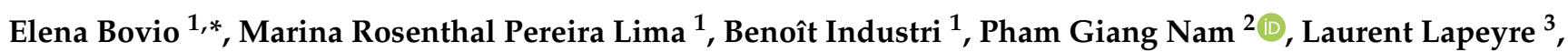 \\ Renaud Canaguier ${ }^{3}$, Laurent Boyer ${ }^{4}$, Mohamed Mehiri ${ }^{2}$ and Michel Ponchet ${ }^{1}$ \\ 1 UMR Institut Sophia Agrobiotech, INRAE, CNRS, UCA, 400 Routes des Chappes, 06903 Sophia Antipolis, \\ France; marinarpl@gmail.com (M.R.P.L.); benoit.industri@inrae.fr (B.I.); michel.ponchet@inrae.fr (M.P.) \\ 2 UMR Nice Institute of Chemistry UCA, CNRS, Marine Natural Products Team, Campus Valrose, \\ 06103 Nice, France; PhamGiangNam_Y1@hus.edu.vn (P.G.N.); Mohamed.Mehiri@unice.fr (M.M.) \\ 3 NIXE Laboratories, 80 Route des Lucioles, 06905 Sophia Antipolis, France; lapeyre@nixe.fr (L.L.); \\ canaguier@nixe.fr (R.C.) \\ 4 UMR INSERM, Mediterranean Centre for Molecular Medicine (C3M) UCA, 151 route Saint Antoine de \\ Ginestière, 06204 Nice, France; boyer1@unice.fr \\ * Correspondence: elena.bovio@inrae.fr \\ + Presented at the 1st International Electronic Conference on Biological Diversity, Ecology and Evolution, \\ 15-31 March 2021; Available online: https:/ /bdee2021.sciforum.net/.
}

check for updates

Citation: Bovio, E.; Lima, M.R.P.; Industri, B.; Nam, P.G.; Lapeyre, L.; Canaguier, R.; Boyer, L.; Mehiri, M.; Ponchet, M. From the Sea to the Field: The Case Study of the Mycobiota Associated to the Marine Sponge Haliclona fulva and Its Interest as Biocontrol Agent Source for Agriculture. Biol. Life Sci. Forum 2021, 2, 5. https://doi.org/10.3390/ BDEE2021-09466

Published: 15 March 2021

Publisher's Note: MDPI stays neutral with regard to jurisdictional claims in published maps and institutional affiliations.

Copyright: (c) 2021 by the authors. Licensee MDPI, Basel, Switzerland. This article is an open access article distributed under the terms and conditions of the Creative Commons Attribution (CC BY) license (https:// creativecommons.org/licenses/by/ $4.0 /)$.

\begin{abstract}
Oceans and seas represent a largely unexplored environment, especially at the microorganism level. Among them, marine fungi are particularly interesting since they exhibit a high diversity and an incredible ability to produce new secondary metabolites that may have a biotechnological interest. In the present study, as part of the Interreg Alcotra FINNOVER project (2017-2021), the goal is to isolate and identify fungi associated to the Mediterranean sponge Haliclona fulva. The obtained strains were further evaluated for their ability to inhibit plant pathogens thanks to the production of active secondary metabolites. Natural strategies based on microorganisms (strains, compounds) have gained an increasing interest in plant protection. They are promising alternatives to some conventional agrochemicals that are banned due to concerns regarding health and the environment. The isolation of fungi was achieved from three specimens of $H$. fulva collected in the same area of the French Riviera. The homogenized sponges were plated on a seawater medium and on potato dextrose agar. The individual colonies were isolated in pure culture and identified (morphological check and sequencing of genomic markers). Overall, 118 different strains were isolated. The use of two different media guarantees to isolate a higher number of strains, but no significant difference was observed in the species isolated from the two culture conditions. The most abundant genera were Penicillium, Trichoderma and Cladosporium. However, the common core mycobiota of the three sponges was represented by Parathyridariella dematiacea, Roussoella padinae, Trichoderma atrobrunneum and different strains of the genus Kalmusia, including new species. Several species isolated from $H$. fulva were exclusive of the marine environment and were never or poorly studied for their biological activity. A selection of these fungi (62 strains) were tested for their ability to inhibit the growth of three important plant pathogens. Preliminary results showed that $34 \%, 43 \%$ and $43 \%$ of evaluated strains clearly inhibited Botrytis cinerea, Phytophthora capsici and Sclerotinia sclerotiorum, respectively. In conclusion, the mycobiota of $H$. fulva was characterized by a huge diversity, including species that are currently studied to be described as new ones. The preliminary results of the biological activity showed that despite the unusual environment studied to find new biocontrol agents for agriculture, several fungi exhibited a promising activity against three major plant pathogens.
\end{abstract}

Keywords: marine fungi; sponges; natural products; bioactivity; biocontrol 
Supplementary Materials: The poster presentation is available online at https: / www.mdpi.com/ article/10.3390/BDEE2021-09466/s1. 